\title{
Photodynamic therapy as an antifungal treatment (Review)
}

\author{
YI LIANG $^{1}$, LI-MING LU ${ }^{1}$, YONG CHEN $^{1}$ and YOU-KUN LIN ${ }^{2}$ \\ ${ }^{1}$ Department of Dermatology, Liuzhou Municipal Liutie Central Hospital, Liuzhou, Guangxi 545007; \\ ${ }^{2}$ Department of Dermatology, The First Affiliated Hospital of Guangxi Medical University, \\ Nanning, Guangxi 530021, P.R. China
}

Received November 30, 2014; Accepted February 9, 2016

DOI: $10.3892 /$ etm.2016.3336

\begin{abstract}
Photodynamic therapy (PDT) involves the systemic or topical application of a photosensitizer (PS), alongside the selective illumination of the target lesion with light of an appropriate wavelength, in order to promote localized oxidative photodamage and subsequent cell death. Numerous studies have demonstrated that PDT is highly effective in the destruction of fungi in vitro. The mechanism underlying the effects of PDT results from the photons of visible light of an appropriate wavelength interacting with the intracellular molecules of the PS. Reactive species are produced as a result of the oxidative stress caused by the interaction between the visible light and the biological tissue. At present, no antifungal treatment based on PDT has been licensed. However, antifungal PDT is emerging as an area of interest for research.
\end{abstract}

\section{Contents}
1. Introduction
2. PDT
3. Mechanisms of PDT
4. PS employed in PDT
5. PDT for fungi
6. In vitro studies
7. In vivo studies
8. Adverse effects of ALA-PDT
9. Limitations and improvement of ALA-PDT
10. Conclusions

\section{Introduction}

Photodynamic therapy (PDT) involves the systemic or topical administration of a photosensitizer (PS), alongside the selective illumination of a target lesion with light of

Correspondence to: Dr You-Kun Lin, Department of Dermatology, The First Affiliated Hospital of Guangxi Medical University, 6 Shuangyong Road, Nanning, Guangxi 530021, P.R. China

E-mail: gz98039@hotmail.com

Key words: photodynamic therapy, fungi an appropriate wavelength, in order to promote localized oxidative photodamage and subsequent cell death $(1,2)$. PDT showed initial success in the treatment of malignant diseases, including skin tumors (3), cutaneous T-cell lymphoma (4) and cervical cancer $(5,6)$, and precancerous lesions, including Bowen's disease (7,8) and Barrett's oesophagus (9). In recent years, PDT has also been used for the treatment of vulgaris, leishmaniasis, acne and bacterial, fungal and viral infections (10-12).

Previous studies demonstrated that PDT was highly effective in the destruction of fungi in vitro $(13,14)$. At present, numerous antifungal drugs, including azoles, have a fungistatic (a delay in growth) rather than fungicidal (a complete inactivation of fungal conidia and hyphae) effect. Fungal conidia have been shown to be less susceptible to antifungal drugs, compared with hyphae $(10,15)$.

It is estimated that $10-20 \%$ of the global population may be affected by mycoses, which are frequently recurrent and chronic (16). Acquisition of fungal pathogens results in significant morbidity causing discomfort, social isolation, disfigurement and may predispose one to bacterial diseases $(17,18)$. However, fungi are eukaryotic organisms and their similarities to mammalian cells have led to significant difficulties in the development of new antifungal drugs. The heavy burden of fungal infections, and the increase in fungal strains resistant to the current antifungals globally (18), has rendered the development of new therapeutic strategies, such as antifungal photodynamic therapy, an urgent requirement.

\section{PDT}

PDT uses a PS and visible light of the appropriate wavelength to generate cytotoxic reactive species in the presence of oxygen. The presence of cytotoxic species in the target site results in the damage of target cells (19). PDT involves delivering visible light of the appropriate wavelength to excite the PS molecule to the excited singlet state (19).

The primary advantages of PDT are that the PS can be targeted to a specific cell or tissue and the visible light can be spatially directed to the infected area (19). In addition, the treatment of localized infections with PDT allows selectivity of the PS for microbes over host cells, delivery of the PS into the lesion and an ability to effectively illuminate the infected area (20). 


\section{Mechanisms of PDT}

The mechanism underlying the effects of PDT results from the photons of visible light of an appropriate wavelength interacting with intracellular molecules of the PS (21). Reactive species are produced as a result of the oxidative stress caused by the interaction between the visible light and the biological tissue, and cells are damaged when the reactive oxygen species overwhelm the biochemical defences of the cell (15). A PS is selectively delivered to the target microbial cells and activated by irradiation with light of the appropriate wavelength when taken up by these cells (22). When the PS is activated, type I and/or type II oxidative mechanisms may occur, which underlie the production of free radicals and singlet oxygen, respectively (23). The type I pathway involves electron-transfer reactions from the PS triplet state to a substrate, which results in the production of radical ions that may then react with oxygen to produce cytotoxic species, including superoxide as well as lipid-derived and hydroxyl radicals (24). The type II pathway involves energy transfer from the PS triplet state to ground state molecular oxygen (triplet) to produce excited-state singlet oxygen, which can oxidize various biological molecules, including nucleic acids, proteins and lipids $(25,26)$. These reactive species may then inactivate microbes by damaging cellular components (25), predominantly via the photo-oxidation of nucleic acids, proteins (27) and membrane lipids (28).

The pathway that dominates (either type I or type II) is determined by the general circumstances, including the PS concentration, conditions in the cellular environment, the physicochemical characteristics of the PS and the chemical properties and morphology of the microbial target structures (29). The physiochemical properties of the PS determine its binding affinity to the cell wall of microorganisms; positively charged PS are typically more effective than negative or neutral ones, since, in the majority of cases, the outer surface of microorganisms is negatively charged (30). After the PS binds to the microbial wall, it may either remain outside the microorganism or be translocated to the inner cell membrane in order to induce light- and/or dark-stimulated wall permeability alterations (31). As well as exogenous-acting PS, protoporphyrin IX, which is produced from its precursor 5-aminolevulinic acid (ALA) in the heme biosynthesis signaling pathway, is an endogenous PS that is also important in antimicrobial PDT (32).

\section{PS employed in PDT}

A PS, a light source and the presence of significant concentrations of molecular oxygen in the target tissue are all required for PDT (33). The features of an ideal PS include the absence of toxicity, toxic by-products and mutagenic effects, an ability to selectively accumulate in the target tissue, a suitability for topical, oral and intravenous administration, and cost-effectiveness (34).

PS that are used in PDT include chlorines, porphyrins, phenothiazines and phthalocyanines. The phenothiazines used in PDT include orthotoluidine blue and methylene blue (35). Phenothiazines have simple tricyclic planar structures and are cationic compounds. The maximum absorption wavelength is $625 \mathrm{~nm}$ for orthotoluidine blue and $656 \mathrm{~nm}$ for methylene blue (35). Porphyrins are tetraazamacrocycle compounds that are widely encountered in nature (36). ALA is metabolized to protoporphyrin IX, thus it is not a PS, but rather a porphyrin precursor (2).

Light penetration is also important in PDT (36); light in the blue region penetrates $1.5 \mathrm{~mm}$ into the tissue, whereas light in the red region penetrates $3.0 \mathrm{~mm}$. The optimal wavelength to promote photo-killing is $\sim 410 \mathrm{~nm}$ (37).

The antifungal action of PDT appears to be strain dependent, and the type of biological medium has been shown to affect the efficacy of PDT in vivo (38). The PS to be used in antifungal PDT must be able to overcome fungal pigments and other substances, as well as the depth of penetration of light into the skin. However, no clinical treatment is currently licensed in the area of antimicrobial PDT (39).

\section{PDT for fungi}

The observed effects of PDT on yeasts and dermatophytes have led to the suggestion of its potential use for the treatment of skin mycoses (21). PDT is cost-effective, highly selective and avoids the occurrence of drug resistant strains (40). Therefore, PDT may become a valuable alternative to the already established antifungal drugs if the in vitro and ex vivo results can be transferred to clinical practice (41).

Trichophyton rubrum causes persisting dermatophytosis, and patients with a compromised immune system may suffer from chronic dermatophytosis (42). The ability of the host's defence mechanisms to overcome a dermatophytic infection has been closely associated with the appearance of the infection. The fungal wall is associated with virulence and is also the frequent target of numerous antifungal agents (43). The outermost layer of the fungal wall consists of $\beta$-glucan, the second layer contains galactomannans and complex glycoproteins attached to a peptide backbone, and the third layer consists primarily of chitin, which gives the fungal wall its rigidity $(44,45)$. The innermost layer of the wall is the cell membrane (46). Typically, it takes conidia $\sim 2 \mathrm{~h}$ to adhere to the skin surface (47). Following the initial attachment to keratinized structures, the conidia germinate and form hyphae, which penetrate the epidermal layer (48). The optimum $\mathrm{pH}$ of the proteinases and some of the keratinases produced by the fungi during this initial stage is acidic (49), corresponding to the $\mathrm{pH}$ of the skin surface in humans. However, in vitro studies with T. rubrum have shown that the $\mathrm{pH}$ of the cultivation medium changes as a function of nutrients used to reach values of pH 8-9 (50). Proteolytic and keratinolytic activity appear to be important virulent factors for dermatophytes.

Typically, the treatment of dermatophytoses involves the administration of an antifungal drug. However, oral antifungal agents may induce side-effects, including hepatotoxicity, and may interact with other drugs (50).

It is important to note that PDT has previously been investigated for the treatment of skin and mucosal infections $(50,51)$. The concentration of the PS in the target tissue and the intensity of photons directed at the target tissue must be considered when evaluating the efficacy of the photodynamic procedure (51). Candida yeasts may cause skin and mucosal infections in patients with local predisposing conditions and are also a major cause of systemic infections, particularly in 
patients with a compromised immune system (52). Studies have demonstrated that PDT was able to inhibit germ tube and biofilm formation, and reduce adhesion to epithelial buccal cells (53). Dovigo et al (54) reported that biofilms were less susceptible to PDT, as compared with their planktonic counterparts. The effect of PDT has been observed against the dermatophyte T. rubrum (25), and two cases of onychomycosis successfully treated with PDT have previously been described, which involved topical application of an ointment containing $20 \%$ ALA.

\section{In vitro studies}

The majority of published work on antifungal PDT has centred on in vitro laboratory investigations, involving the use of various fungi, PS and irradiation protocols $(55,56)$. At present, there have been no reports on the development of resistance to antifungal PDT, and the treatment has not been associated with mutagenic effects or genotoxicity. The effects of PDT have predominantly been observed against the dermatophyte T. rubrum $(57,58)$.

\section{In vivo studies}

The clinical efficacy of ALA-PDT in the treatment of fungal infections of human skin has previously been investigated (57). Mutagenic effects of photodynamic treatment with chloroaluminum phthalocyanine and RPL068 were not found in Kluyveromyces marxianus (58) nor Candida albicans (59). Following a primary search of 106 articles on databases including, MEDLINE, EMBASE and the Cochrane Library to evaluate the efficacy and safety of PDT for superficial mycoses, it was determined that only seven papers involving 63 patients with superficial mycoses were included. The PS used in all patients was $20 \%$ ALA (42).

\section{Adverse effects of ALA-PDT}

The overall tolerability of ALA-PDT has been shown to be good, although the adverse effects of ALA-PDT for treating superficial mycoses included a burning sensation during irradiation, erythema, pain, edema and blistering (57).

\section{Limitations and improvement of ALA-PDT}

ALA-PDT can be used as a long-term treatment without causing the accumulation of protoporphyrin IX in normal skin (60). ALA is a hydrophilic, zwitterionic molecule with a molecular weight of $167.6 \mathrm{~g} / \mathrm{mol}$ (61). It is difficult for ALA to penetrate through intact skin $(62,63)$; therefore, improving delivery systems for ALA in the skin will have an important role in the clinical application of ALA-PDT. The enhancement of ALA skin penetration may include physical methods, such as ultrasound, laser, microneedles and iontophoresis, the addition of chemical penetration enhancers, including oleic acid and dimethyl sulfoxide, or the use of lipophilic ALA derivatives or various vehicles to improve the transdermal delivery of ALA (64). Lipophilic ALA ester derivatives may have an enhanced potential for clinical use $(65,66)$. In previous studies, several strategies were used in order to improve
ALA penetration into the skin, including iontophoresis (67), lasers (68), microneedles and ultrasound (69).

Mechanisms of penetration enhancers include disruption of the highly ordered structure of stratum corneum lipids, interaction with intercellular proteins and improved partitioning of the drug, co-enhancer, or solvent into the stratum corneum (69). Electron microscopy revealed that a discreet lipid domain is induced within the stratum corneum lipid bilayers upon exposure to oleic acid, which enhanced the permeation of drugs across the skin (54) Friedberg et al (70) reported that oleic acid was able to optimize the skin delivery of ALA in PDT.

The half-life of ALA in the body is $\sim 45 \mathrm{~min}$ (70). Vehicles may serve as a solubilization matrix (71). Liposomes, which are microscopic vesicles consisting of one or more membrane-like phospholipid bilayers surrounding an aqueous medium $(72,73)$, are one of the best drug delivery systems for low molecular-weight drugs, such as ALA (74,75).

At present, PDT is used for the prevention and treatment of a variety of malignant skin tumors and inflammatory diseases, including non-melanoma skin cancer, actinic keratoses, acne vulgaris, photorejuvenation, and hidradenitis suppurativa $(76,77)$.

In vitro studies demonstrated that ALA was sufficiently metabolized into protoporphyrin IX and was able to effectively kill T. rubrum and C. albicans (77).

\section{Conclusions}

PDT includes the systemic or topical administration of a PS, alongside the selective illumination of a target lesion with light of the appropriate wavelength, in order to cause localized oxidative photodamage and subsequent cell death. Numerous studies have demonstrated that PDT is highly effective in the destruction of fungi in vitro. However, at present, no clinical treatment based on PDT has been licensed. The current study presents in vitro and in vivo and human studies that support antifungal PDT as a new approach against mycoses. In conclusion, antifungal PDT is emerging as an area of interest in the discovery of novel antifungal therapeutic strategies.

\section{References}

1. Wainwright M: Photodynamic antimicrobial chemotherapy (PACT). J Antimicrob Chemother 42: 13-28,1998.

2. Plaetzer K, Krammer B, Berlanda J, Berr F and Kiesslich T: Photophysics and photochemistry of photodynamic therapy: Fundamental aspects. Lasers Med Sci 24:259-268, 2009.

3. 3. Bagnato VS, Kurachi C, Ferreira J, Marcassa LG, Sibata CH and Allison RR: PDT experience in Brazil: A regional profile. Photodiagnosis Photodyn Ther 2: 107 118, 2005.

4. Calzavara-Pinton PG, Venturini M and Sala R: A comprehensive overview of photodynamic therapy in the treatment of superficial fungal infections of the skin. J Photochem Photobiol B 78: 1-6, 2005.

5. Yu J, Hsu CH, Huang CC and Chang PY: Development of therapeutic Au-methylene blue nanoparticles for targeted photodynamic therapy of cervical cancer cells. ACS Appl Mater Interfaces 7: 432-441, 2015.

6. de Freitas LM, Soares CP and Fontana CR: Synergistic effect of photodynamic therapy and cisplatin: A novel approach for cervical cancer. J Photochem Photobiol B 140: 365-373, 2014.

7. Gracia-Cazaña T, López MT, Oncins R and Gilaberte Y: Successful treatment of sequential therapy in digital Bowen's disease with methyl aminolevulinate photodynamic therapy and topical diclofenac 3\% in hyaluronan $2.5 \%$ gel. Dermatol Ther (Heidelb) 28: 341-343, 2015. 
8. Jung SE, Kim SK and Kim YC: Photodynamic therapy in Bowen disease of the first web space of the hand. Ann Dermatol 27:76-78, 2015.

9. Trushina OI, Novikova EG, Sokolov VV, Filonenko EV, Chissov VI and Vorozhtsov GN: Photodynamic therapy of virus-associated precancer and early stages cancer of cervix uteri. Photodiagn Photodyn Ther 5: 256-259, 2008.

10. Cassidy CM, Tunney MM, McCarron PA and Donnelly RF: Drug delivery strategies for photodynamic antimicrobial chemotherapy: From benchtop to clinical practice. J Photochem Photobiol B 95: 71-80, 2009.

11. Wang Q, Yuan D, Liu W, Chen J, Lin X, Cheng S, Li F and Duan X: Use of Optical Fiber Imported Intra-Tissue Photodynamic Therapy for Treatment of Moderate to Severe Acne Vulgaris. Med Sci Monit 22: 362-366, 2016.

12. Al-Qahtani A, Alkahtani S, Kolli B, Tripathi P, Dutta S, Al-Kahtane AA, Jiang XJ, Ng DK and Chang KP: Amino-phthalocyanine-mediated photodynamic inactivation of Leishmania tropica. Antimicrob Agents Chemother: Jan 11, 2016 (Epub ahead of print). AAC: 01879-15, 2016.

13. Gupta AK, Einarson TR, Summerbell RC and Shear NH: An overview of topical antifungal therapy in dermatomycoses. A North American perspective. Drugs 55: 645-674, 1998.

14. Calzavara-Pinton PG, Venturini M, Capezzera R, Sala R and Zane C: Photodynamic therapy of interdigital mycoses of the feet with topical application of 5-aminolevulinic acid. Photodermatol Photoimmunol Photomed 20: 144-147, 2004.

15. Henderson BW and Dougherty TJ: How does photodynamic therapy work? Photochem Photobiol 55: 145-157, 1992.

16. Drake LA, Dinehart SM, Farmer ER, Goltz RW, Graham GF, Hordinsky MK, Lewis CW, Pariser DM, Skouge JW, Webster SB, et al: Guidelines/Outcomes Committee. American Academy of Dermatology: Guidelines of care for superficial mycotic infections of the skin: Tinea capitis and tinea barbae. J Am Acad Dermatol 34: 290-294, 1996.

17. Brown GD, Denning DW, Gow NA, Levitz SM, Netea MG and White TC: Hidden killers: Human fungal infections. Sci Trans Med 4: 165rv13, 2012.

18. Cowen LE: The evolution of fungal drug resistance: Modulating the trajectory from genotype to phenotype. Nat Rev Microbiol 6 : 187-198, 2008.

19. Soergel $P$ and Hillemanns P: Photodynamic therapy for intraepithelial neoplasia of the lower genital tract. Photodiagn Photodyn Ther 7: 10-14, 2010.

20. Smijs TG and Pavel S: The susceptibility of dermatophytes to photodynamic treatment with special focus on Trichophyton rubrum Photochem Photobiol 87: 2-13, 2011.

21. Hamblin MR and Hasan T: Photodynamic therapy: A new antimicrobial approach to infectious disease? Photochem Photobiol Sci 3: 436-450, 2004.

22. Maisch T: A new strategy to destroy antibiotic resistant microorganisms: Antimicrobial photodynamic treatment. Mini Rev Med Chem 9: 974-983, 2009.

23. Wilson BC and Patterson MS: The physics, biophysics and technology of photodynamic therapy. Phys Med Biol 53: R61-R109, 2008.

24. Athar M, Mukhtar H and Bickers DR: Differential role of reactive oxygen intermediates in photofrin-I- and photofrin-II-mediated photoenhancement of lipid peroxidation in epidermal microsomal membranes. J Invest Dermatol 90: 652-657, 1988.

25. Redmond RW and Gamlin JN: A compilation of singlet oxygen yields from biologically relevant molecules. Photochem Photobiol 70: 391-475, 1999.

26. Phoenix DA and Harris F: Light activated compounds as antimicrobial agents - patently obvious? Recent Pat Antiinfect Drug Discov 1: 181-199, 2006

27. Jori G and Coppellotti O: Inactivation of pathogenic microorganisms by photodynamic techniques: Mechanistic aspects and perspective applications. Antiinfect Agents Med Chem 6: 119-131, 2007.

28. Smijs TG and Schuitmaker HJ: Photodynamic inactivation of the dermatophyte Trichophyton rubrum. Photochem Photobiol 77: $556-560,2003$.

29. Girotti AW and Kriska T: Role of lipid hydroperoxides in photo-oxidative stress signaling. Antioxid Redox Signal 6 : 301-310 2004.

30. Bertoloni G, Zambotto F, Conventi L, Reddi E and Jori G: Role of specific cellular targets in the hematoporphyrin-sensitized photoinactivation of microbial cells. Photochem Photobiol 46: 695-698, 1987
31. Merchat M, Bertolini G, Giacomini P, Villanueva A and Jori G: Meso-substituted cationic porphyrins as efficient photosensitizers of gram-positive and gram-negative bacteria. J Photochem Photobiol B 32: 153-157, 1996

32. Lee JW, Kim BJ and Kim MN: Photodynamic therapy: New treatment for recalcitrant Malassezia folliculitis. Lasers Surg Med 42: 192-196, 2010.

33. Allison RR, Downie GH, Cuenca R, Hu XH, Childs CJ and Sibata $\mathrm{CH}$ : Photosensitizers in clinical PDT. Photodiagn Photodyn Ther 1: 27-42, 2004.

34. Magalhães JL, Moreira LM, Rodrigues-Filho UP, Giz MJ, Pereira-da-Silva MA, Landers R, Vinhas RCG, Nascente PAP: Surface chemistry of iron tetraazamacrocycle on the aminopropyl-modified surface of oxidized $\mathrm{n}-\mathrm{Si}(100)$ by AFM and XPS. Surf Interface Anal 33: 293-298, 2002.

35. Moreira LM, dos Santos FV, Lyon JP,Maftoum-Costa M, Pacheco-Soares C and da Silva NA: Photodynamic therapy: Porphyrins and phthalocyanines as photosensitizers. J Chem 61: 741-754, 2008.

36. Moreira LM, Ribelatto JC and Imasato H: Ruffled and planar conformations of the porphyrin ring in complexes and heme proteins: Physical-chemistry properties and spectroscopic implications. Quim Nova 27: 958-963, 2004 (In Portuguese).

37. Nyman ES and Hynninen PH: Research advances in the use of tetrapyrrolic photosensitizers for photodynamic therapy. J Photochem Photobiol B 73: 1-28, 2004.

38. Plaetzer K, Krammer B, Berlanda J, Berr F and Kiesslich T: Photophysics and photochemistry of photodynamic therapy: Fundamental aspects. Lasers Med Sci 24: 259-268, 2009.

39. Calzavara-Pinton P, Rossi MT, Sala R and Venturini M: Photodynamic antifungal chemotherapy. Photochem Photobiol 88: 512-522, 2012

40. Maisch T, Szeimies RM, Lehn N and Abels C: Antibacterial photodynamic therapy. A new treatment for superficial bacterial infections? Hautarzt 56: 1048-1055, 2005 (In German).

41. Ragàs X, Agut $M$ and Nonell S: Singlet oxygen in Escherichia coli: New insights for antimicrobial photodynamic therapy. Free Radic Biol Med 49: 770-776, 2010.

42. Odom R: Dermatologic manifestations of AIDS. J Am Podiatr Med Assoc 78: 127-129, 1988.

43. Martinez-Rossi NM, Peres NT and Rossi A: Antifungal resistance mechanisms in dermatophytes. Mycopathologia 166: 369-383, 2008.

44. Grappel SF, Bishop CT and Blank F: Immunology of dermatophytes and dermatophytosis. Bacteriol Rev 38: 222-250, 1974

45. San-Blas G: The cell wall of fungal human pathogens: Its possible role in host-parasite relationships. Mycopathologia 79: $159-184,1982$

46. Deacon JW: The moulds of man. In: Fungal Biology. Blackwell Publishing Ltd, pp322-338, 2006.

47. Zurita $\mathrm{J}$ and Hay RJ: Adherence of dermatophyte microconidia and arthroconidia to human keratinocytes in vitro. J Invest Dermatol 89: 529-534, 1987.

48. Apodaca G and McKerrow JH: Regulation of Trichophyton rubrum proteolytic activity. Infect Immun 57: 3081-3090, 1989.

49. Brasch J and Zaldua M: Enzyme patterns of dermatophytes. Mycoses 37: 11-16, 1994

50. Maranhão FC, Paião FG and Martinez-Rossi NM: Isolation of transcripts over-expressed in human pathogen Trichophyton rubrum during growth in keratin. Microb Pathog 43: 166-172, 2007.

51. Gupta AK and Cooper EA: Update in antifungal therapy of dermatophytosis. Mycopathologia 166: 353-367, 2008.

52. Lyon JP, Costa SC, Totti VMG, Munhoz MF and de Resende MA Predisposing conditions for Candida spp. carriage in the oral cavity of denture wearers and individuals with natural teeth. Can J Microbiol 52: 462-467, 2006.

53. Munin E, Giroldo LM, Alves LP and Costa MS: Study of germ tube formation by Candida albicans after photodynamic antimicrobial chemotherapy (PACT). J Photochem Photobiol B 88: 16-20, 2007.

54. Dovigo LN, Pavarina AC, Mima EG, Giampaolo ET, Vergani CE and Bagnato VS: Fungicidal effect of photodynamic therapy against fluconazole-resistant Candida albicans and Candida glabrata. Mycoses 54: 123-130, 2011.

55. Fuchs BB, Tegos GP, Hamblin MR and Mylonakis E: Susceptibility of Cryptococcus neoformans to photodynamic inactivation is associated with cell wall integrity. Antimicrob Agents Chemother 51: 2929-2936, 2007. 
56. Prates RA, Kato IT, Ribeiro MS, Tegos GP and Hamblin MR Influence of multidrug efflux systems on methylene blue-mediated photodynamic inactivation of Candida albicans. J Antimicrob Chemother 66: 1525-1532, 2011.

57. Calzavara-Pinton PG, Venturini M, Capezzera R, Sala R and Zane C: Photodynamic therapy of interdigital mycoses of the feet with topical application of 5-aminolevulinic acid. Photodermatol Photoimmunol Photomed 20: 144-147, 2004.

58. Smijs TGM, Bouwstra JA, Schuitmaker HJ, Talebi M and Pavel S: A novel ex vivo skin model to study the susceptibility of the dermatomycete Trichophyton rubrum to photodynamic treatment in different growth phases. J Antimicrob Chemother 59: 433-440, 2007.

59. Peres NT, Sanches PR, Falcão JP, Silveira HC, Paião FG, Maranhão FC, Gras DE, Segato F, Cazzaniga RA, Mazucato M, et al: Transcriptional profiling reveals the expression of novel genes in response to various stimuli in the human dermatophyte Trichophyton rubrum. BMC Microbiol 10: 39, 2010.

60. Akilov OE, Kosaka S, O'Riordan K and Hasan T: Parasiticidal effect of delta-aminolevulinic acid-based photodynamic therapy for cutaneous leishmaniasis is indirect and mediated through the killing of the host cells. Exp Dermatol 16: 651-60, 2007.

61. Wiegell SR, Stender IM, Na R and Wulf HC: Pain associated with photodynamic therapy using 5-aminolevulinic acid or 5-aminolevulinic acid methylester on tape-stripped normal skin. Arch Dermatol 139: 1173-1177, 2003.

62. Sil S, Bose T, Roy D and Chakraborti AS: Protoporphyrin IX-induced structural and functional changes in human red blood cells, haemoglobin and myoglobin. J Biosci 29: 281-291, 2004.

63. Di Venosa G, Hermida L, Fukuda H, Defain MV, Rodriguez L, Mamone L, MacRobert A, Casas A and Batlle A: Comparation of liposomal formulations of ALA Undecanoyl ester for its use in photodynamic therapy. J Photochem Photobiol B 96: 152-158, 2009.

64. Morrow DI, McCarron PA, Woolfson AD, Juzenas P, Juzeniene A, Iani V, Moan J and Donnelly RF: Hexyl aminolaevulinate is a more effective topical photosensitiser precursor than methyl aminolaevulinate and 5-aminolaevulinic acids when applied in equimolar doses. J Pharm Sci 99: 3486-3498, 2010.

65. van den Akker JT, Iani V, Star WM, Sterenborg HJ and Moan J: Topical application of 5-aminolevulinic acid hexyl ester and 5-aminolevulinic acid to normal nude mouse skin: Differences in protoporphyrin IX fluorescence kinetics and the role of the stratum corneum. Photochem Photobiol 72: 681-689, 2000.
66. Gaullier JM, Berg K, Peng Q, Anholt H, Selbo PK, Ma LW and Moan J: Use of 5-aminolevulinic acid esters to improve photodynamic therapy on cells in culture. Cancer Res 57: 1481-1486, 1997.

67. Lopez RF, Bentley MV, Begoña Delgado-Charro M and Guy RH: Optimization of aminolevulinic acid delivery by iontophoresis. J Control Release 88: 65-70, 2003.

68. Kacerovska D, Pizinger K, Kumpova M and Cetkovska P: Genital warts treated by photodynamic therapy. Skinmed 6: 295-297, 2007.

69. Mikolajewska P, Donnelly RF, Garland MJ, Morrow DI, Singh TR, Iani V, Moan J and Juzeniene A: Microneedle pre-treatment of human skin improves 5-aminolevulininc acid (ALA)- and 5-aminolevulinic acid methyl ester (MAL)-induced PpIX production for topical photodynamic therapy without increase in pain or erythema. Pharm Res 27: 2213-2220, 2010.

70. Friedberg JS, Skema C, Baum ED, Burdick J, Vinogradov SA, Wilson DF, Horan AD and Nachamkin I: In vitro effects of photodynamic therapy on Aspergillus fumigatus. J Antimicrob Chemother 48: 105-107, 2001.

71. Fang JY, Hong CT, Chiu WT and Wang YY: Effect of liposomes and niosomes on skin permeation of enoxacin. Int J Pharm 219: 61-72, 2001

72. Allison RR, Downie GH, Cuenca R, et al: Photosensitizers in clinical PDT. Photodiagnosis Photodyn Ther 1: 27-42, 2004.

73. Kamp H, Tietz HJ, Lutz M, Piazena H, Sowyrda P, Lademann J and Blume-Peytavi U: Antifungal effect of 5-aminolevulinic acid PDT in Trichophyton rubrum. Mycoses 48: 101-107, 2005.

74. Zucker D, Marcus D, Barenholz Y and Goldblum A: Liposome drugs' loading efficiency: A working model based on loading conditions and drug's physicochemical properties. J Control Release 139: 73-80, 2009.

75. Fang JY: Nano- or submicron-sized liposomes as carriers for drug delivery. Chang Gung Med J 29: 358-362, 2006.

76. Huang L, Huang YY, Mroz P, Tegos GP, Zhiyentayev T, Sharma SK, Lu Z, Balasubramanian T, Krayer M, Ruzié C, et al: Stable synthetic cationic bacteriochlorins as selective antimicrobial photosensitizers. Antimicrob Agents Chemother 54: 3834-3841, 2010.

77. Qiao J, Li R, Ding Y and Fang H: Photodynamic therapy in the treatment of superficial mycoses: An evidence-based evaluation. Mycopathologia 170: 339-343, 2010. 